\title{
Tasas de erosión e índices geomorfológicos en tres cuencas costeras al sur de la península de Baja California, México
}

\author{
José Octavio Navarro Lozano ${ }^{1, *}$, Enrique Nava Sánchez², Enrique Troyo Dieguez ${ }^{3}$, \\ José Luis Cadena Zamudio ${ }^{4}$ \\ ${ }^{1}$ Comisión Nacional del Agua (CONAGUA), Subdirección de Asistencia Técnica-Operativa. Chiapas No. 2535, Col. Los Olivos, CP \\ 23040, La Paz, BCS. \\ ${ }^{2}$ Instituto Politécnico Nacional, Centro Interdisciplinario de Ciencias Marinas. Av. Instituto Politécnico Nacional s/n, Col. Playa Palo \\ de Santa Rita, Apdo. Postal 592. CP 23096, La Paz, BCS. \\ ${ }^{3}$ Centro de Investigaciones Biológicas del Noroeste, S.C., Mar Bermejo No. 195, Col. Playa Palo de Santa Rita, Apdo. Postal 128, CP \\ 23090, La Paz, BCS. \\ ${ }^{4}$ Universidad Autónoma del Estado de Hidalgo, Instituto de Ciencias Básicas e Ingeniería, Área Académica de Ciencias de la Tierra y \\ Materiales. Ciudad Universitaria, Km 4.5 Carretera Pachuca - Tulancingo, Col. Carboneras, CP 42184, Mineral de la Reforma, Hgo \\ *jnavarro@conagua.gob.mx; joseoctavio.navarro@gmail.com
}

\section{Resumen}

Las cuencas de drenaje costeras del sur de la península de Baja California forman parte importante en la estabilidad del sistema de celdas litorales de su costa, como fuentes principales de sedimentos. Las cuencas Migriño, El Salto y El Tule son vulnerables a la erosión debido a las pendientes empinadas del terreno y a su ubicación, ya que en esta parte de la península tienen mayor influencia las precipitaciones intensas asociadas a los huracanes que se presentan en verano. Con el uso de la fórmula RUSLE (Revised Universal Soil Loss Equation) y los índices geomorfológicos obtenidos mediante la aplicación de técnicas de SIG, se evaluó la distribución espacial de las tasas de erosión hídrica y su relación con las unidades litológicas, rasgos geomorfológicos, distribución de suelos y patrones estructurales. Esto permitió conocer el control que ejercen la distribución del suelo y los rasgos geomorfológicos sobre la distribución de tasas de erosión dentro de cada una de las cuencas de drenaje. Las tasas de erosión de moderadas $\left(0.1 \mathrm{a} 0.5 \mathrm{Mg} \mathrm{ha}^{-1}\right.$ año $\left.{ }^{-1}\right)$ a altas $(0.5$ a $2 \mathrm{Mg} \mathrm{ha}^{-1}$ año $^{-1}$ ) se asocian a pendientes iguales o mayores a $15^{\circ}$, (principalmente laderas de montañas) y a suelos tipo litosol-regosol; tasas de erosión bajas $\left(0-0.1 \mathrm{Mg} \mathrm{ha}^{-1}\right.$ año $\left.{ }^{-1}\right)$ se asocian a pendientes menores a $5^{\circ}$ (lomeríos y planicies), con suelos tipo regosol. El análisis de los índices geomorfológicos muestra que las cuencas de drenaje son jóvenes, asociadas a actividad neotectónica moderada a baja, evidenciada principalmente por el control estructural en la parte alta de las cuencas. En la parte media y baja de las cuencas los cambios en los índices geomorfológicos indican control estructural bajo, en donde se presentan procesos erosivos y de sedimentación.

Palabras clave: Tasas de erosión, geología estructural, Bahía San Lucas, RUSLE, sedimentos.

\begin{abstract}
Coastal drainage basins in the southern part of the peninsula of Baja California are an important part for the stability of the littoral cell system of the coast in Baja California, because they are the major sediment sources. Migriño, El Salto and El Tule watersheds are vulnerable to erosion due to the steep slopes and geographic location because in this part of the peninsula rainfall associated with summer hurricanes has a mayor influence. Using the RUSLE equation (Revised Universal Soil Loss Equation) and geomorphologic indexes, obtained by GIS techniques, we assessed the spatial distribution of erosion rates and its relationship to lithology, geomorphic features, soil distribution and structural patterns. This allowed us to know the control that soil distribution and geomorphic features exert on the distribution of erosion rates within each drainage basin. Moderate (0.1 to $\left.0.5 \mathrm{Mg} \mathrm{ha}^{-1} \mathrm{year}^{-1}\right)$ to high (0.5 to $2 \mathrm{Mg}^{\mathrm{h} \mathrm{a}^{-1}}$
\end{abstract}


year ${ }^{-1}$ ) erosion rates are associated to slopes equal to or greater than $15^{\circ}$ (mountain slopes), and Litosol-Regosol types; low erosion rates $\left(0-0.1 \mathrm{Mg} \mathrm{ha}^{-1}\right.$ year $\left.{ }^{-1}\right)$ are associated to slopes of less than $5^{\circ}$ (gentle hill slopes and plains), and Regosol types. Analyses of geomorphologic indexes show that river drainage basins are young, and are associated to moderate or negligible neotectonic activity, as evidenced primarily by structural control in the upper basin. Changes in geomorphologic indexes in the middle and lower basins, where erosion and depositional processes are occurring, indicate little structural control.

Keywords: Erosion rates, structural control, San Lucas Bay, RUSLE, sediments.

\section{Introducción}

La importancia de las cuencas de drenaje en la dinámica costera, radica en que son las principales fuentes de aporte de sedimentos hacia los ambientes sedimentarios costeros presentes en una celda litoral (Inman, 2003), tales como el sistema playa-duna, deltas y abanicos-deltas. Es por ello que la mayor parte de los cambios geomorfológicos que ocurren en dichos ambientes se asocian a las fluctuaciones en las descargas de sedimentos provenientes de las cuencas de drenaje (Best y Griggs, 1991; Komar, 1998; Bird, 2001; Inman, 2003; Walling y Collins, 2008).

Las variaciones de las tasas de erosión, dentro de una cuenca de drenaje, son producto de varios factores ambientales, entre los más importantes están los tectónicos, con influencia en periodos largos y los climáticos, en periodos cortos y largos; sin olvidar el impacto antropogénico. Este último es el factor más dinámico y sus efectos se ven reflejados a corto plazo (meses o años). Existen indicadores asociados a la geomorfología conocidos como índices geomorfológicos (Bull y McFadden, 1977; Hack, 1973; Canon, 1976), mediante los cuales se puede inferir la actividad tectónica en una región. La combinación de las tasas de erosión y los índices geomorfológicos permiten conocer el estado sedimentario en una cuenca de drenaje, es decir, si los procesos dominantes son los erosivos o acrecionarios. El propósito de este estudio es conocer la relación que existe entre las tasas de erosión en las cuencas de drenaje con factores topográficos (pendiente del terreno) y geomorfológicos (índices geomorfológicos), y los tipos de suelos presentes en el área de estudio.

\section{1. Área de estudio}

Las cuencas de drenaje Migriño, El Salto y El Tule se localizan en el extremo sur de la península de Baja California (Figura 1a). Estas cuencas son pequeñas, cubren áreas de 202.6, 199.1 y $112.0 \mathrm{~km}^{2}$ respectivamente y son de forma asimétrica o elongada. Las corrientes fluviales que se presentan en ellas son efímeras debido a que conducen agua solamente durante las lluvias o hasta unas pocas horas o días después de éstas. Los arroyos principales en las cuencas Migriño y El Salto son de quinto orden y en la de El Tule, es de cuarto orden. Los patrones de drenaje que dominantes en estas cuencas son de tipo paralelo y subparalelo, aunque también están presentes el subdendritico, y radial. Los tipos paralelo y subparalelo presentan control estructural asociado al fallamiento normal con rumbo Noreste. La litología en el área de estudio está representada por afloramientos de rocas plutónicas del Cretácico y del Terciario, por rocas sedimentarias del Cuaternario, y por rocas metamórficas del Mesozoico (Figura 1a). El complejo metamórfico está formado por orto y paragneis de alto grado de metamorfismo, así como anfibolitas y migmatitas (Shaaf et al., 2000); este complejo aflora al norte de la desembocadura de la cuenca Migriño. Las rocas plutónicas compuestas por Granitotonalita $(\mathrm{K}(\mathrm{Gd}-\mathrm{Tn}))$ cubren la mayor parte de la cuenca Migriño, y la parte alta y los flancos de las cuencas El Salto y El Tule. Las rocas graníticas ( $\mathrm{T}(\mathrm{Gr})$ ) afloran en lomeríos y sierras bajas cercanas a la costa. Los depósitos sedimentarios del Cuaternario comprenden depósitos de conglomerados (cg), intercalaciones de conglomerados y areniscas (ar-cg) pertenecientes a depósitos de abanicos aluviales y afloran en la parte central de las cuencas de drenaje y en los cauces de mayor orden.

El bloque tectónico de Cabo San Lucas (Frizzel et al., 1984) presenta un sistema complejo de fallas principalmente terciarias. Dichas fallas se han relacionado con el proceso de apertura del Golfo de California. El fallamiento principal muestra un rumbo NNW (Fletcher y Munguía-Orozco, 2000). El análisis estructural del área de estudio hizo evidentes dos patrones de fallamiento principal, uno con rumbo NNE y otro perpendicular a éste, con rumbo NNW. Además, se pudo observar que ambos fallamientos afectan mayormente a la cuenca de drenaje Migriño y que las áreas con mayor densidad de fracturas en las cuencas de drenaje El Salto y El Tule se localizan en la parte alta de las cuencas.

Con respecto a los suelos, en las cuencas se presentan tres tipos: (1) Litosol-Regosol, (2) Regosol, y (3) Fluvisol (Figura 1b). La asociación litosol-regosol son suelos de poco desarrollo con espesores menores a $10 \mathrm{~cm}$ sobreyaciendo directamente a las rocas originales. En la cuenca Migriño estos suelos cubren casi la totalidad del área, en El Salto la distribución se restringe a los flancos de la parte alta de la cuenca y en el flanco oriental de la parte baja, y en El Tule se presentan en los flancos de la parte alta de la cuenca. El suelo regosol es de textura gruesa y fase física pedregosa, con espesores generalmente bajos que varían con la pendiente del terreno, llegando a alcanzar hasta un metro en la parte baja de las cuencas. En la cuenca Migriño el regosol sólo 


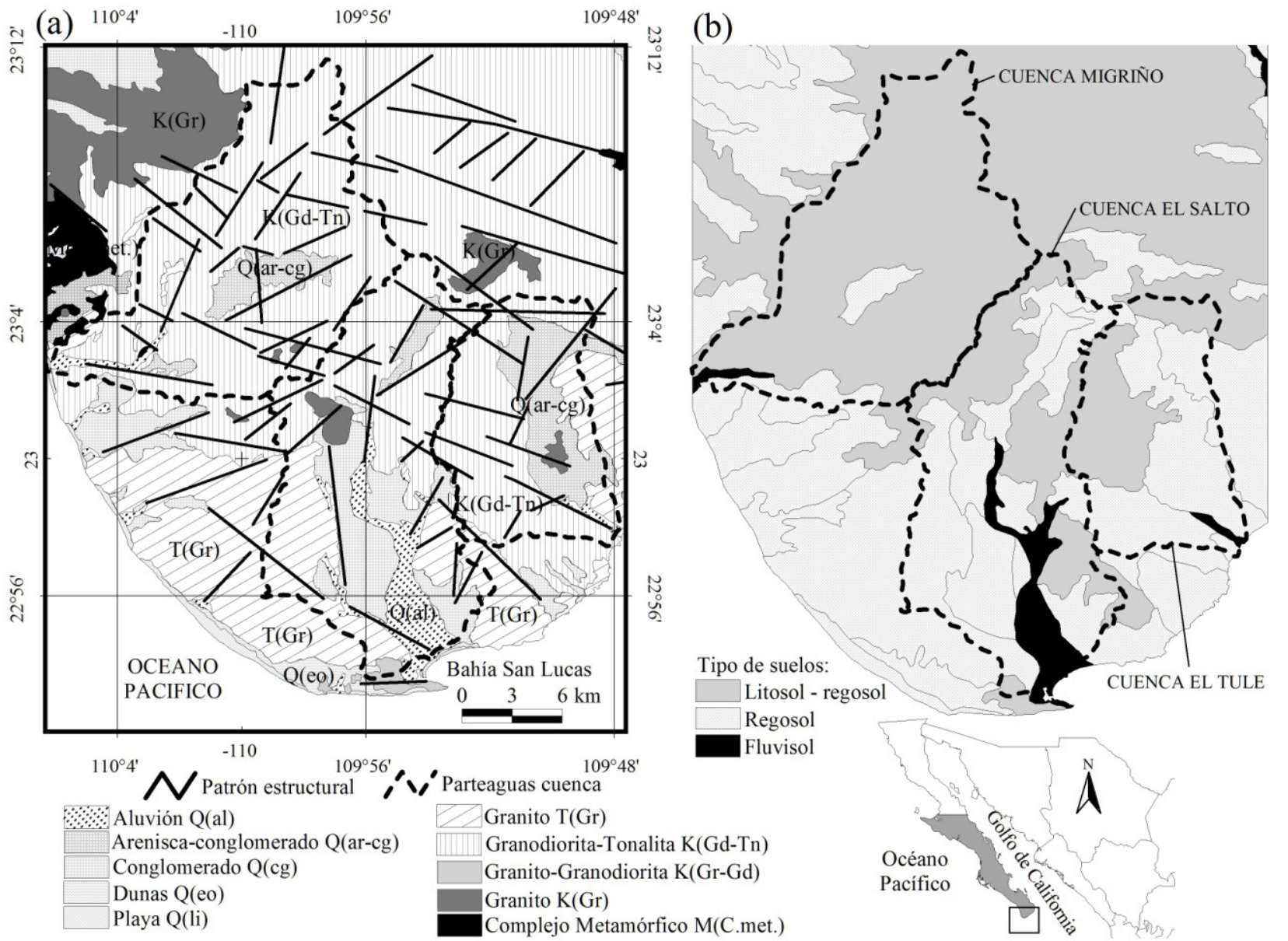

Figura 1. Localización del área de estudio, litología, patrón estructural y suelos presentes en el área de estudio. Carta Geológica San José del Cabo (INEGI, 1984); Carta Edafológica San José del Cabo (INEGI, 1984), ambas cartas escala 1:250000. El parteaguas de las cuencas está delimitado por la línea punteada.

se presenta en la parte media de la cuenca, en donde se ha desarrollado un valle intramontano y en el flanco sur de la parte baja de la cuenca. De manera contraria, en El Salto y El Tule el regosol se distribuye en la mayor parte de las cuencas, desde las partes altas hasta las partes bajas. El suelo tipo fluvisol está formado sobre depósitos aluviales recientes, su distribución se asocia a los valles de los arroyos principales, en donde la pendiente no es tan pronunciada. Las mayores coberturas del fluvisol se localizan en el arroyo El Salto, mientras que en El Tule y Migriño sólo se presentan en un área pequeña próxima a la desembocadura.

El clima predomínate para la región sur de la península de Baja California es seco y extremoso con lluvias escasas, clasificado como árido semi-árido de acuerdo con la clasificación propuesta por Köppen y adaptada para la república mexicana por García (1981). La temperatura media anual en esta zona varia de $22{ }^{\circ} \mathrm{C}$ a $24^{\circ} \mathrm{C}$, mientras que la temperatura media mensual fluctúa entre $27^{\circ} \mathrm{C}$ a $30^{\circ} \mathrm{C}$ en los meses de verano. La precipitación media anual es del orden de $397 \mathrm{~mm}$ en la zona montañosa, al norte del poblado de Cabo san Lucas, y de $205 \mathrm{~mm}$ en las partes bajas y hacia el litoral.

Por su posición geográfica la parte sur de la península se encuentra en la trayectoria de los ciclones tropicales que se desarrollan en el Pacífico Oriental, en los meses de mayo a octubre. Durante estos eventos, la topografía favorece la generación de flujos torrenciales y de depósito que ocurre sobre el piedemonte, valles fluviales y zona litoral, en donde se desarrollan generalmente abanicos aluviales y abanicos deltas. Navarro-Lozano (2006) señala que la ocurrencia de huracanes tipo 1, de acuerdo con la escala de Saffir-Simpson, dentro de un radio de $500 \mathrm{~km}$ con respecto a Cabo San Lucas, tiene un promedio de 3.5 eventos por año, para un radio de $300 \mathrm{~km}$ es de 2 eventos por año y para un radio de $100 \mathrm{~km}$, las posibilidades son de un evento ciclónico cada 6 años aproximadamente. A partir de 1950 hasta el 2002, se han presentado 17 eventos dentro del radio de $100 \mathrm{~km}$.

\section{Metodología}

\subsection{Geomorfología}

A partir del modelo digital de elevación y del modelo raster de pendientes del terreno se obtuvo el mapa geomorfológico. Para ello, se utilizo la extensión Topographic Position Index 
(TPI) v. 1.2 desarrollada por Jenness (2006). El TPI es la diferencia de la elevación topográfica en una celda con respecto al promedio de la elevación de las celdas vecinas. Para este estudio se considero un radio de vecindad de 250 m. Para la clasificación de las formas se utilizó como base la propuesta por Weiss (2001) que consta de 10 clases, la cual se ajusto a 3 clases porque son las que mejor representan las geoformas principales en las cuencas estudiadas.

\subsection{Erosión}

La media anual de la erosión de las laderas $(\mathrm{H})$ fue calculada utilizando La Ecuación Universal Revisada de pérdida de suelo (RUSLE por sus siglas en inglés) (Renard et al., 1994). Las unidades de esta ecuación están dadas en toneladas por hectárea por año $\left(\mathrm{Mg} \mathrm{ha}^{-1} \mathrm{año}^{-1}\right)$, y es el producto de seis factores: erodabilidad por la lluvia (R); erodabilidad del suelo (K), longitud de la pendiente (L), gradiente de la pendiente $(\mathrm{S})$, uso del suelo y vegetación (C), y prácticas de conservación $(\mathrm{P})$.

$$
\mathrm{H}=\mathrm{RKLSCP}
$$

Esta fórmula ha sido ampliamente aplicada en la predicción de la erosión y planes de conservación en diferentes partes del mundo (Mitasova y Mitas, 1999; Onori et al., 2006; Montes-León et al., 2011) y la comparación con otros métodos ha sido discutida en varios trabajos (e.g. Phillips, 1991; Wasson et al., 1996; Faran Ali y De Boer, 2003; McKergow et al., 2005). En el área de estudio no existen prácticas de conservación del suelo por lo que el factor $\mathrm{P}$, es considerado con valor 1 , de acuerdo a lo señalado por Simms et al., (2003). Los valores obtenidos por la aplicación de la fórmula RUSLE fueron clasificados en cuatro rangos de erosión hidrica media: baja $(0-0.1)$; moderada $(0.1-0.5)$; alta $(0.5-2)$; y muy alta $(2-5)$.

La base de datos para la aplicación RUSLE incluye representaciones digitales del mapa de suelos, uso de suelo y vegetación, archivos tipo shape de las cuencas y red de drenaje, y un Modelo Digital de Elevación del terreno (MDE). Se utilizo el SIG Arcview 3.2 para calcular los modelos raster.

\subsection{Densidad de drenaje}

Se define como la longitud total $(\Sigma \mathrm{L})$ de los cauces dentro de la cuenca, dividida entre el área total de drenaje (A):

$$
\mathrm{Dd}=\Sigma \mathrm{L} / \mathrm{A}\left(\mathrm{km} \mathrm{km}^{-2}\right)
$$

Se utilizó como información base el MDE y la red de cauces, y como plataforma al SIG ArcView 3.2, y las extensiones 3D Analyst, Spatial Analyst, y Drainage/ Lineament/Road/density Analyst extensión Versión 1.0 desarrollada por Saraf (2001).
2.4. Índices geomorfológicos como indicadores de actividad tectónica

Existen numerosos índices geomorfológicos que permiten conocer el estado tectónico actual de alguna zona. En este trabajo se usan aquellos que se consideran que dan mejor información. Los índices empleados y sus ecuaciones fueron los siguientes:

\subsection{1. Índice de la forma de la cuenca. Se obtiene de la ecuación:}

$$
\mathrm{B}_{\mathrm{s}}=\mathrm{B}_{1} \mathrm{~B}_{\mathrm{w}}^{-1}
$$

donde $\mathrm{B}_{1}$ es la longitud de la cuenca; $\mathrm{y}_{\mathrm{w}}$ es el ancho de la cuenca. La escala utilizada para este análisis fue 1:50000.

\subsubsection{Sinuosidad del frente montañoso $\left(S_{m f}\right)($ Bull y \\ McFadden, 1977)}

Se obtiene de la ecuación:

$$
\mathrm{S}_{\mathrm{mf}}=\mathrm{L}_{\mathrm{mf}} \mathrm{Ls}^{-1}
$$

donde $\mathrm{L}_{\mathrm{mf}}$ es la longitud total real del frente montañoso; y Ls es la longitud en línea recta medida entre los extremos del frente.

\subsection{3. Índice del gradiente de perfil longitudinal del cauce del arroyo (SL)(Hack, 1973).}

Se obtiene de la ecuación:

$$
\mathrm{SL}=\left(\Delta \mathrm{h} \Delta \mathrm{l}^{-1}\right) * \mathrm{~L}
$$

donde $\Delta \mathrm{h}$, es el incremento de la altura; $\Delta \mathrm{l}$, la distancia horizontal que corresponde en cada caso al $\Delta \mathrm{h}, \mathrm{y} \mathrm{L}$, es la longitud acumulada desde el punto inicial hasta la desembocadura del arroyo.

\subsubsection{Relación anchura del fondo del valle / altura del valle $\left(V_{f}\right)($ Bull y McFadden, 1977; Bull, 1978). \\ Se obtiene de la ecuación:$$
\mathrm{V}_{\mathrm{f}}=2 \mathrm{~V}_{\mathrm{fw}}[(\text { Eld-Esc })+(\text { Erd-Esc })]^{-1}
$$

donde $\mathrm{V}_{\mathrm{f}}$ también es conocido como valor del encajamiento; $\mathrm{V}_{\mathrm{fw}}$ es el ancho del valle del río (se suele tomar un valor mínimo de ancho de cauce, en este caso fue de $50 \mathrm{~m}$, adecuado para una escala 1:50000); Eld-Esc es la diferencia de nivel máximo de la ladera derecha del valle, menos la cota a la que está el cauce del río en la misma transversal; y (Erd-Esc) es la misma diferencia pero en la ladera izquierda. Cuanto más ancho sea el río y menos altas las divisorias de su cuenca de drenaje, mayor será el valor del índice obtenido.

Bull y McFadden (1977) a partir de la comparación de los índices $\mathrm{S}_{\mathrm{mf}} \mathrm{y}_{\mathrm{f}}$ proponen una clasificación de los frentes montañosos que consta de tres clases: (Clase 1) frentes tectónicamente activos, con valores de $\mathrm{S}_{\mathrm{mf}}<1.6$ y de $\mathrm{V}_{\mathrm{f}}<$ 0.5; (Clase 2) frentes de moderada actividad, con valores de $\mathrm{S}_{\mathrm{mf}}$ cercanos o $>2$ y de $\mathrm{V}_{\mathrm{f}}$ pueden ser de hasta 1,4; y (Clase 3) frentes inactivos con valores altos $>3 \mathrm{de}_{\mathrm{mf}} \mathrm{y} \mathrm{V}_{\mathrm{f}}$. 


\section{Resultados}

\subsection{Geomorfología}

En la cuenca Migriño dominan las sierras y cauces en cañones con disección profunda, y en menor medida lomeríos y planicies asociadas a valles intramontanos como los que se ubican en la parte alta y media de esta cuenca (Figura 2a). La planicie está limitada a la parte baja del arroyo Migriño, en donde se localiza la zona de almacenamiento. La pendiente del terreno en esta cuenca es de fuertemente inclinada a muy inclinada (Figura 3b) de acuerdo con la clasificación propuesta por Demek (1972). En las laderas de cerros y en cauces de arroyos con paredes rocosas las pendientes son de $15^{\circ}$ a $35^{\circ}$ y en algunos casos mayores a $35^{\circ}$ (precipitosa).

En la cuenca El Salto dominan los lomeríos, lomeríos disectados y planicies, y se localizan en la parte media y baja de la cuenca. La pendiente del terreno en esta zona es de plana $\left(<2^{\circ}\right)$ a fuertemente inclinada $\left(5^{\circ}-15^{\circ}\right)$ y está asociada al valle fluvial de los arroyos Salto Seco y El Salto, y a los depósitos de piedemonte que se han desarrollado en la base de la sierra en el flanco oriental de la cuenca. Las sierras bajas y sierras altas se localizan en la parte alta y flanco oriental de esta cuenca. En esta misma zona los cauces son de incisión profunda y están encañonados por rocas graníticas. En la parte alta de esta cuenca también se encuentran valles intramontanos con pendientes menores a $2^{\circ}$.

En la cuenca El Tule las geoformas son muy similares a las que se presenta en la cuenca El Salto. Los lomeríos y planicies se presentan en la desembocadura de la cuenca y a todo lo largo del flanco oriental, así como en la parte baja del flanco occidental. Las sierras bajas y sierras altas, se localizan mayormente en el flanco occidental y parte alta de la cuenca. La presencia de cañones también está restringida a esta zona.

\subsection{Tasas de erosión hídrica}

El resultado de La distribución espacial de las tasas de erosión en las cuencas Migriño, El Salto y El Tule se muestran en la Figura 3. En la cuenca de drenaje Migriño la tasa de erosión que domina es la moderada y se distribuye

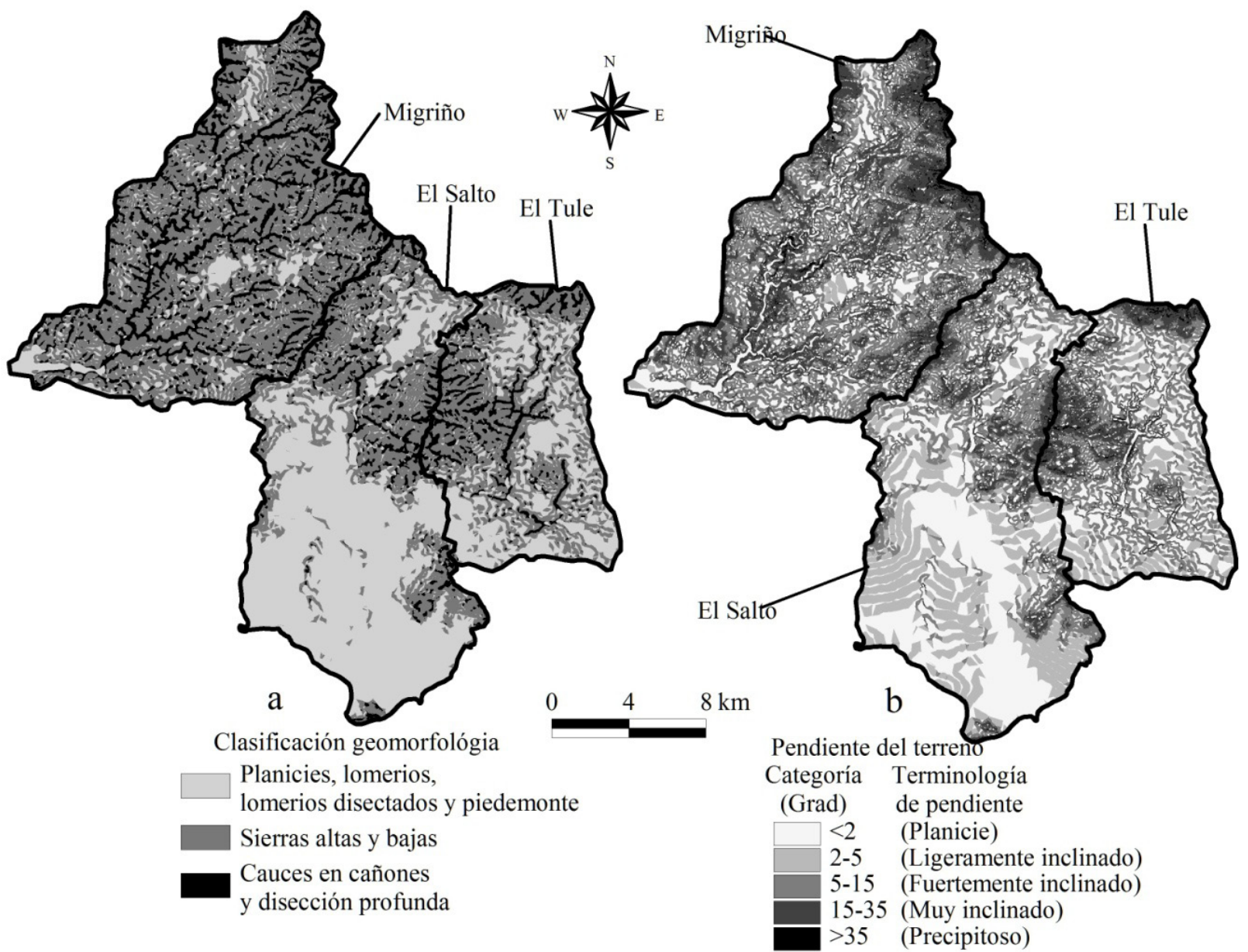

Figura 2. Modelo de pendiente del terreno (a) y unidades geomorfológicas (b), estos mapas fueros obtenidos con el análisis de la información base en el Sistema de Información Geográfica ArcView 3.2. 
en la mayor parte del área de esta cuenca (Figura 3, Tabla 1). Esta erosión está asociada a las sierras altas y bajas con rango de pendientes de $15^{\circ}$ a $35^{\circ}$ (Figura 2a) y el tipo de suelo es litosol-regosol (Figura $2 \mathrm{~b}$ ). La erosión alta se restringe a la parte alta de la cuenca, en donde se tienen sierras altas con pendientes igual o mayores a $35^{\circ}$ y el suelo es litosol-regosol. De manera contraria, la erosión baja se distribuye en zonas aisladas con desarrollo de valles intramontanos y algunas planicies pequeñas, con pendiente del terreno generalmente menor a $5^{\circ}$.

En la cuenca El Salto, la tasa de erosión baja es la que domina la mayor parte del área de la cuenca. Ésta se presenta localmente en el valle intramontano que se ha desarrollado en la parte alta de la cuenca, así como en la parte media y baja de la cuenca en donde la geoforma dominante es el piedemonte, lomeríos y planicies, con una

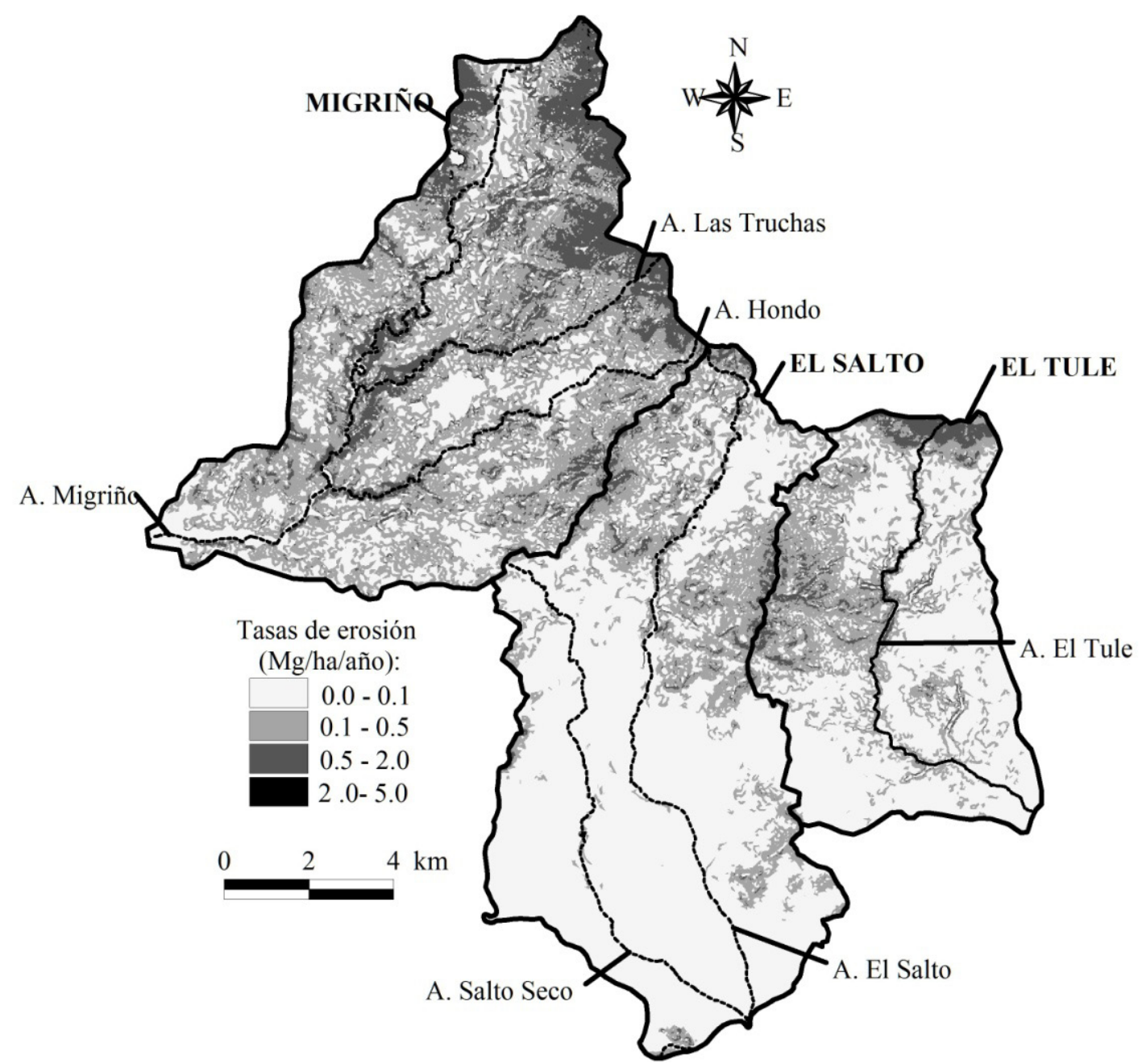

Figura 3. Modelo de erosión en las cuencas de drenaje estudiadas aplicando la Ecuación Universal de Erosión del Suelo Revisada (RUSLE). La letra A indica "arroyo".

Tabla 1. Porcentaje que cubre cada uno de los intervalos de erosión hídrica con respecto a la superficie en hectáreas en cada una de las cuencas de drenaje.

\begin{tabular}{|c|c|c|c|c|c|c|}
\hline \multirow{3}{*}{$\begin{array}{l}\text { Tasa de erosión } \\
\text { (ton/ha/año) }\end{array}$} & \multicolumn{6}{|c|}{ Sin practicas de conservación } \\
\hline & \multicolumn{2}{|c|}{ Cuenca Migriño } & \multicolumn{2}{|c|}{ Cuenca El Saltito } & \multicolumn{2}{|c|}{ Cuenca El Tule } \\
\hline & Superficie (ha) & $\%$ & Superficie (ha) & $\%$ & Superficie (ha) & $\%$ \\
\hline Baja $(0-0.1)$ & 4919.9 & 24.3 & 13988.4 & 70.3 & 5972.3 & 53.3 \\
\hline Moderado (0.1 a 0.5$)$ & 10131.9 & 50.0 & 5110.1 & 25.7 & 4257.1 & 38.0 \\
\hline Alta $(0.5-2)$ & 5172.6 & 25.5 & 800.0 & 4.0 & 968.1 & 8.6 \\
\hline Muy alta $(2-5)$ & 20.8 & 0.1 & 0.0 & 0.0 & 0.0 & 0.0 \\
\hline
\end{tabular}


pendiente del terreno igual o menor a $5^{\circ}$ (Figura $2 \mathrm{a}$ y b). En esta misma área el Regosol es el suelo dominante y el Fluvisol, también presente, se restringe al cauce del arroyo principal (Figura 1b). La erosión moderada se presentan en la parte alta de la cuenca asociada a las sierras baja, en donde la pendiente es de $5^{\circ}$ a $15^{\circ}$ y la erosión alta se restringe a las partes altas de la sierra en donde la pendiente es mayor a $35^{\circ}$.

La erosión que domina en la cuenca El Tule es de moderada a baja. La erosión baja se asocia a los lomeríos y planicies donde la pendiente del terreno es menor a $5^{\circ}$ y el suelo es tipo regosoles. Mientras que la erosión moderada se presenta en la parte alta de la cuenca donde están presentes las sierras bajas con pendientes mayores a $15^{\circ}$ en donde el tipo de suelo es Litosol-Regosol. La erosión alta está muy localizada en la parte alta y en el flanco izquierdo de la cuenca, en la cima de las sierras altas en donde la pendiente es igual o mayor a $35^{\circ}$ y existe la asociación litosol-regosol.

\subsection{Orden de corriente y densidad de drenaje}

La corriente principal en las cuencas Migriño y El Salto es de quinto orden, mientras que en la cuenca El Tule es de cuarto orden (Figura 4a). Ésto refleja que estas cuencas son amplias y concuerdan con los órdenes máximos reportados para otras cuencas en diferentes áreas en la península de Baja California. Lo anterior también concuerda con lo reportado por Blair y McPherson (1994) quienes mencionan que la red de drenaje en las cuencas en zonas áridas o desérticas se caracteriza por cauces efímeros con pendientes pronunciadas y longitud corta, que pueden alcanzar el quinto orden. Las corrientes de primer orden en la cuenca
Migriño y El Salto representan el $68 \%$ de la red de drenaje, mientras que en la cuenca El Tule alcanzan el 70\%. Estos cauces son angostos y cortos, y la pendiente promedio está relacionada a la pendiente de las laderas en donde se han desarrollado. En los cauces de primer orden es en donde se inicia el transporte del sedimento hacia cauces de mayor orden dentro de la cuenca.

Sobreponiendo la red de drenaje sobre el modelo de pendiente del terreno se observa que la mayoría de los cauces de primer orden en Migriño tienen pendientes que varían de $5^{\circ}$ a $10^{\circ}$, aunque los mismos cauces de primer orden localizados en la parte alta de las montañas tienen pendientes que varían de $10^{\circ}$ a $20^{\circ}$. Estas relaciones contrastan con las pendientes desarrolladas por los cauces de primer orden en las cuencas El Salto y El Tule, con un promedio menor a $5^{\circ}$ y solamente los cauces de la parte alta de las sierras tienen pendientes que varían de $5^{\circ}$ a $10^{\circ}$. Los valores de densidad de drenaje en las cuencas de estudio varían de 0.001 a $0.1 \mathrm{~km} / \mathrm{km}^{2}$ (Figura $4 \mathrm{~b}$ ).

\section{4. Índices geomorfológicos y almacenamiento aluvial}

\subsubsection{Forma de la cuenca $\left(B_{s}\right)$}

Cuanto mayor sea el valor del índice $\mathrm{B}_{\mathrm{s}}$ (cuencas alargadas), las cuencas son más jóvenes, lo cual suele estar ligado a una mayor actividad tectónica (Carvajal y Sanz de Galdeano, 2008). Con el tiempo y conforme avanza la erosión, las cuencas tienden a ser más amplias en relación a su longitud (Canon, 1976; Ramírez-Herrera, 1998). Los valores de $\mathrm{B}_{\mathrm{s}}$ para las cuencas de drenaje Migriño, El Salto y El Tule son $1.80 ; 2.30$ y 1.80 respectivamente.
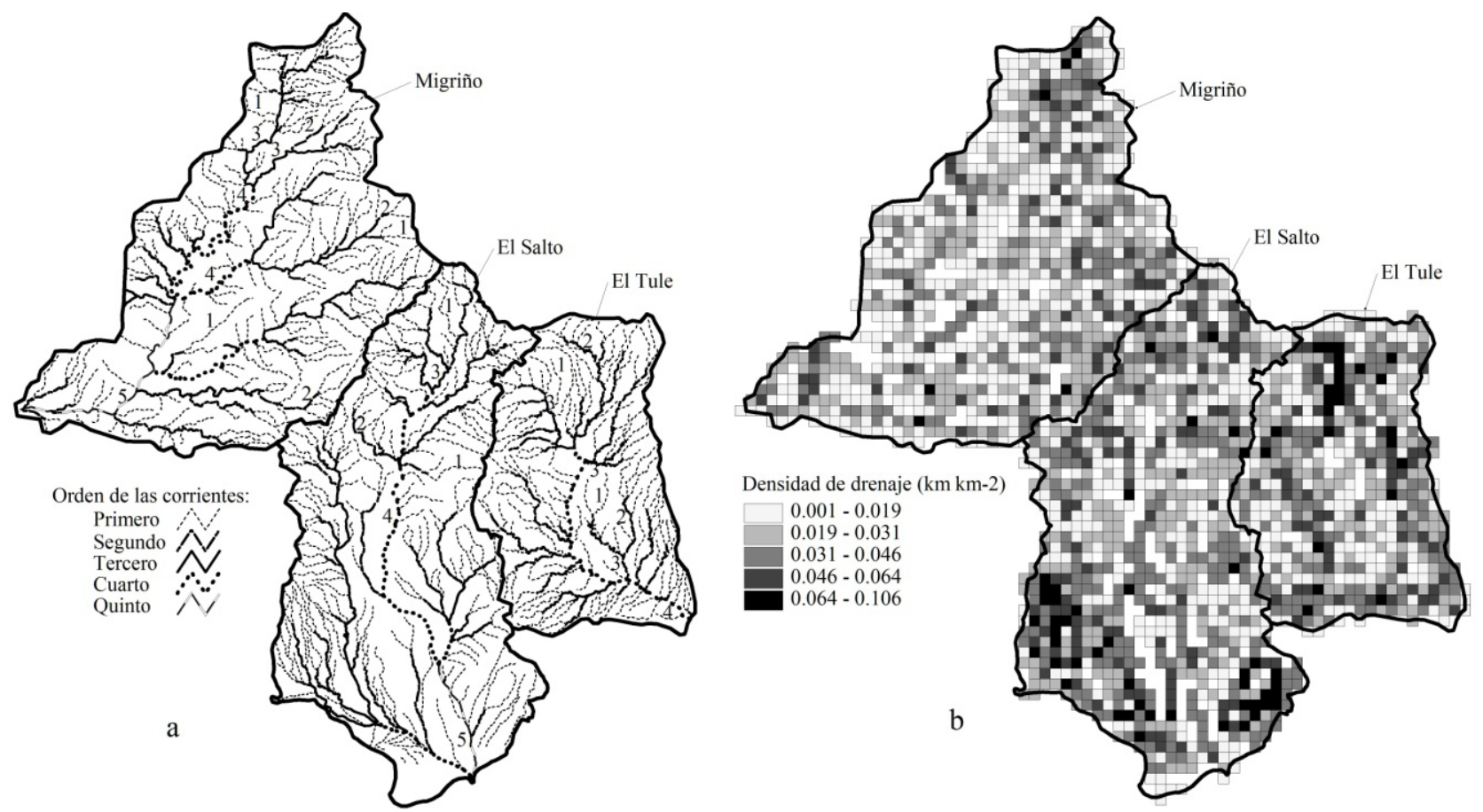

Figura 4. Ordenes de corrientes (a) y distribución de la densidad de drenaje (b). 


\subsubsection{Sinuosidad del Frente montañoso $\left(S_{m f}\right)$}

Los valores cercanos a la unidad del $\mathrm{S}_{\mathrm{mf}}$ indican mayor actividad de una falla. Las fallas activan dan lugar a frentes montañosos aproximadamente rectos, y se hacen sinuosos con el tiempo debido a la erosión (Carvajal y Sanz de Galdeano, 2008).

En la cuenca Migriño no fue posible definir valores de sinuosidad de frentes montañosos debido a que no existen zonas claras de un cambio entre montañas y valles. Sin embargo, en las cuencas El Salto y El Tule se definieron 6 y 5 frentes montañosos respectivamente (Figura 5).

En la cuenca El Salto, se definen tres frentes montañosos: 1) Sierra La Calavera, en el norte de la cuenca, 2) Sierra La Chinche, en la parte media y margen oriental de la cuenca, y 3) Sierra Las Pelonas, en la parte baja y flanco oriental de la cuenca (Figura 5). La Sierra La Calavera está definida por cañones y cerros que sobrepasan los $900 \mathrm{msnm}$ y está constituida por granodioritas-tonalitas cretácicas; este frente montañoso tiene una longitud de $5.40 \mathrm{~km}$ y su índice $\mathrm{S}_{\mathrm{mf}}$ es de 1.15. La Sierra La Chinche presenta un rumbo NE-SW, con alturas mayores a los $900 \mathrm{msnm}$, con una fisiografía de cerros, cañadas y lomeríos hacia la base de la sierra; en esta sierra se definieron tres frentes montañosos, cuya longitud varía entre 2,40 y $5.40 \mathrm{~km}$ y los valores de $\mathrm{S}_{\mathrm{mf}}$ son 1.25 , 1.29 y 1.40 , con promedio de 1.30. La Sierra Las Pelonas tiene una orientación NW-SE, con cerros más bajos que en las sierras anteriores, con alturas que alcanzan los 500 msnm, las cañadas también son de menor profundidad y las rocas dominantes son granitos terciarios; los dos frentes montañosos tiene longitudes entre 4.80 y $5.10 \mathrm{Km}$ y el índice $\mathrm{S}_{\mathrm{mf}}$ es de 1.12 y 1.45, con un promedio de 1.28.

En la cuenca de drenaje El Tule se marcaron cinco frentes montañosos. Dos corresponden a la Sierra La Chinche, ubicada en la margen centro-occidental de la cuenca de drenaje, orientada NE-SW, con altura máxima de $960 \mathrm{msnm}$, y compuesta por la granodiorita-tonalita cretácica. Estos frentes tienen longitudes de 3.50 y $3 \mathrm{~km}$, con $\mathrm{S}_{\mathrm{mf}}$ de 1.37 y 1.08 respectivamente, y un promedio de 1.22 . Los otros tres frentes montañosos corresponden a la sierra El Alamito, orientada NW-SE, una atura mayor a $1000 \mathrm{msnm}$,

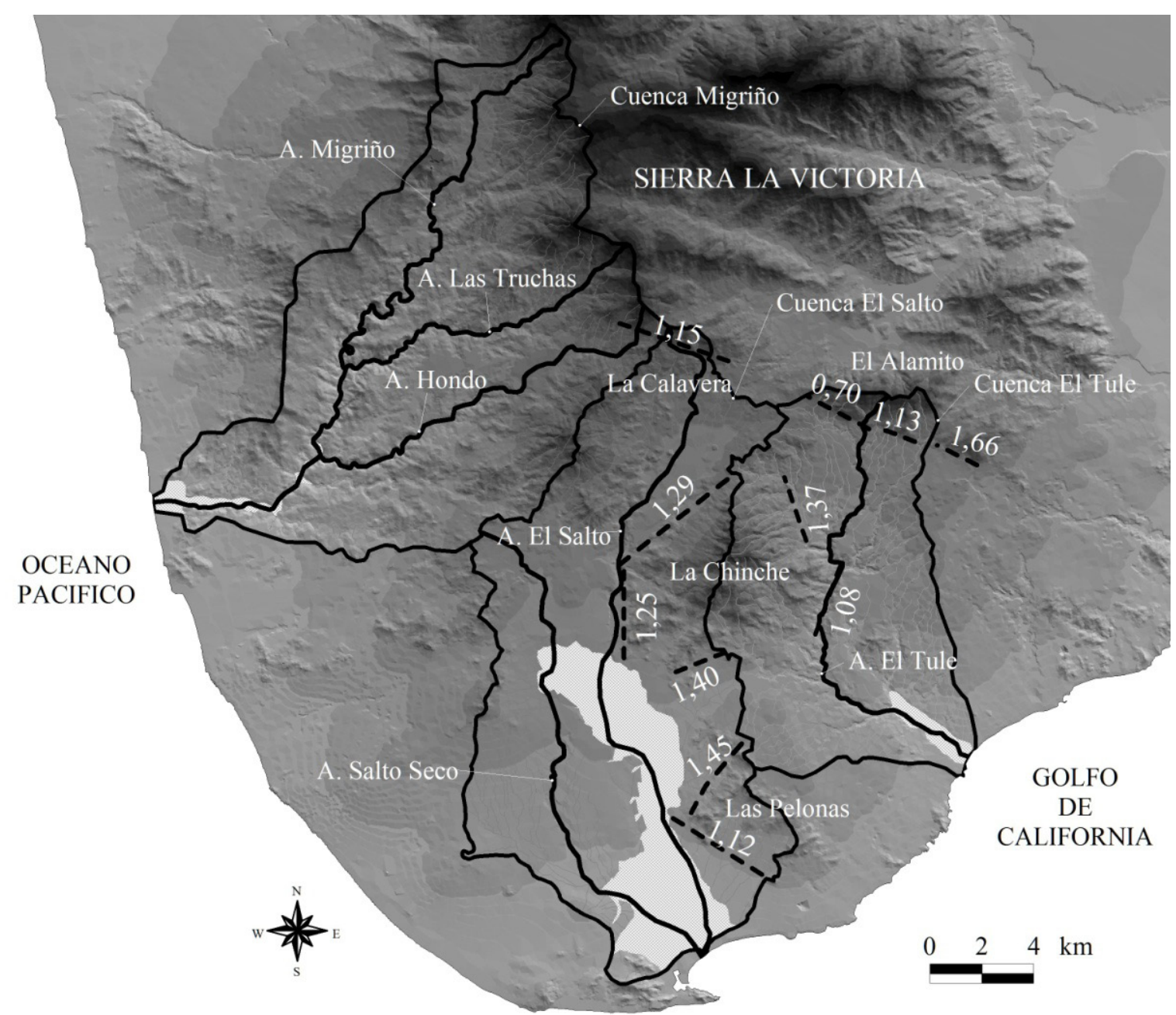

Figura 5. Ubicación de los frentes de montaña y los valores de este índice en cada una de las cuencas de drenaje. El área en color claro indica la zona de almacenamiento aluvial. El mapa base utilizado es el modelo digital de elevación (MDE). 
y compuesta por la granodiorita-tonalita Cretácica y el granito terciario. Estos frentes tienen longitudes de 1,90, 1.50 y $1.70 \mathrm{~km}$, y sus índices $\mathrm{S}_{\mathrm{mf}}$ son de $0.70,1.13$ y 1.66 respectivamente, con un promedio de 1.20 (Figura 5).

\subsubsection{Gradiente del perfil longitudinal del cauce del arroyo (SL)}

Este índice permite evaluar las relaciones entre la actividad tectónica, la litología (resistencia a la erosión) y la topografía.

En la cuenca Migriño el perfil topográfico del arroyo Migriño muestra valores de SL que varían entre 13.7 y 15.7 (Figura 6), y la pendiente del terreno es de fuertemente inclinada $\left(15^{\circ}-35^{\circ}\right)$ a precipitosa $\left(>35^{\circ}\right)$ en los primeros $1000 \mathrm{~m}$ longitudinales del perfil. Se considera que estos valores de SL aplican para los arroyos Las Truchas y Hondo, ya que la forma de la parte alta de los perfiles es similar a la de Migriño. En el perfil del arroyo Migriño se observan cambios topográficos evidenciados por valores "anómalos" de 22.1, 149.5 y 15.1. En el arroyo Hondo los valores de SL varían de 28.28 a 11.52. En general el valor de SL decrece de las cabeceras de los arroyos hacia la desembocadura. El perfil topográfico del arroyo Las Truchas es parecido a la del arroyo Migriño con pendiente pronunciada en la parte alta y cambios abruptos de pendiente en la parte media, lo cual se considera que es debido al control estructural, más que a la litología (Figura 6, cuenca Migriño). La zona de almacenamiento aluvial se localiza en la desembocadura de la cuenca; inicia a los $200 \mathrm{~m}$ de altitud y se extiende hasta el litoral, cubre un área de $3.2 \mathrm{~km}^{2}$. La pendiente máxima en esta zona es de $9.9^{\circ}$ y se presenta en el área en donde confluyen los arroyos Migriño y Hondo, esta pendiente disminuye hasta $0.4^{\circ}$ hacia la desembocadura de la cuenca.

Los valores de SL en la cuenca El Salto son menores que los obtenidos para Migriño (Figura 6). En la parte alta del arroyo El Salto, SL varían de 9 a 7.10, mientras que en la cabecera del arroyo Salto Seco el valor es de 1.6. Estos valores disminuyen aguas abajo en ambos arroyos y solamente se presentan un par datos anómalos ligeramente mayores a 5 , relacionados con la ubicación de terrazas en depósitos antiguos de abanicos aluviales (Navarro-Lozano, 2006). La zona de almacenamiento aluvial inicia a los $350 \mathrm{~m}$ de altitud y cubre un área de $33.2 \mathrm{~km}^{2}$. La pendiente máxima en esta zona es de $6^{\circ}$ y disminuyen a $2^{\circ}$ hacia la

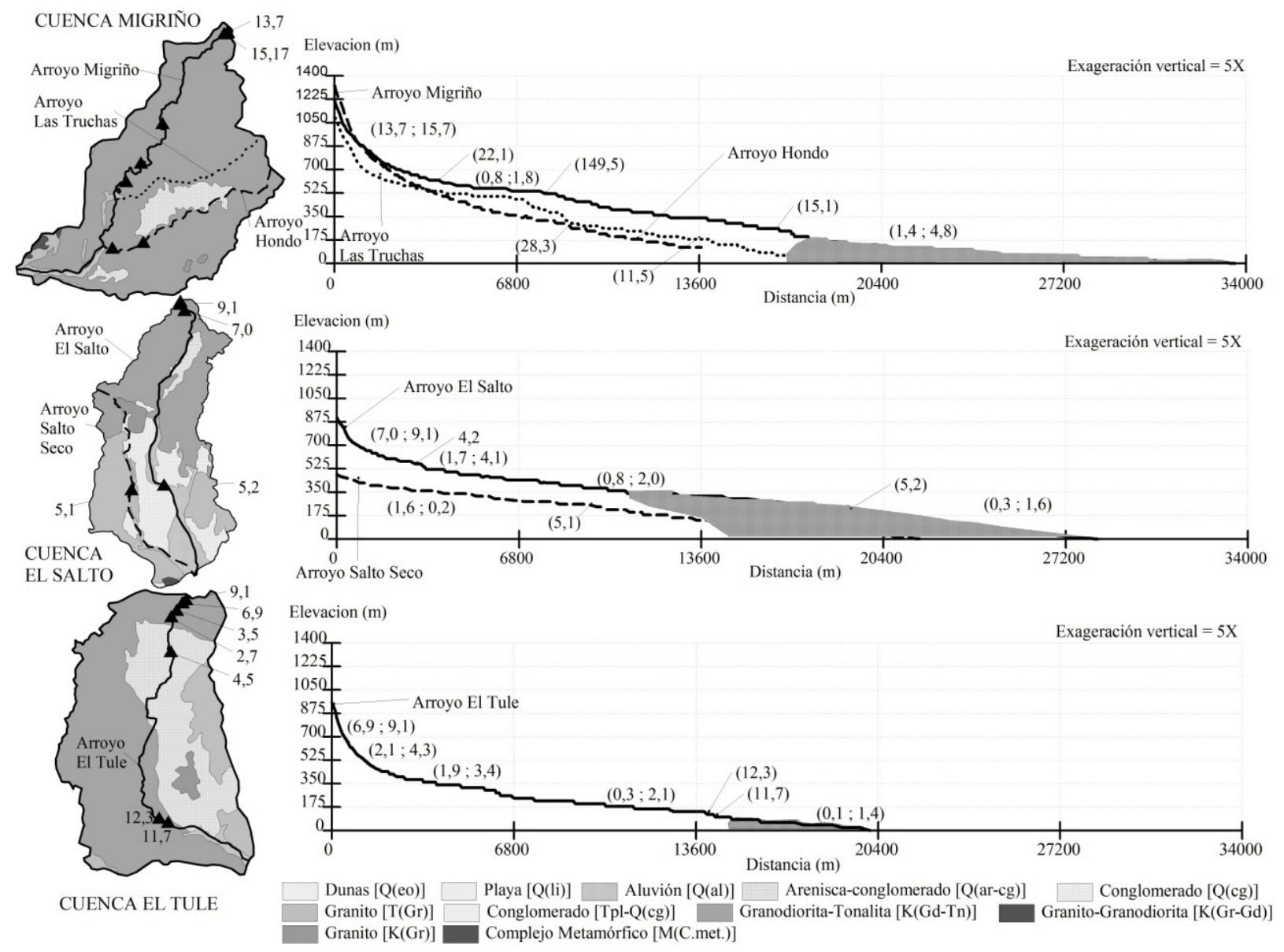

Figura 6. Unidades litológicas que afloran en cada una de las cuencas de drenaje, Perfil longitudinal de los principales arroyos en las cuencas y el símbolo de triangulo indica los puntos con valores de Gradiente del perfil longitudinal del cauce del arroyo (SL). El área achurada, en la parte baja del perfil topográfico, indica la ubicación de las zonas de almacenamiento aluvial. 
desembocadura de la cuenca.

En la cuenca El Tule, SL varía de 6.10 a 9.10 en la parte alta del arroyo. Estos valores disminuyen aguas abajo, aunque, aproximadamente a $200 \mathrm{msnm}$ se observan valores anómalos de 11.7 y 12.3, los cuales están asociados a cambios litológicos (Figura 6). La zona de almacenamiento aluvial inicia por debajo de los $170 \mathrm{~m}$ de altitud y cubre un área de $2.7 \mathrm{~km}^{2}$, con una pendiente máxima de $4.1^{\circ}$ con un promedio de $0.9^{\circ}$.

\subsubsection{Relación entre la anchura y la altura del valle $\left(V_{f}\right)$}

Cuanto más alto sea el valor del índice de encajamiento $\left(\mathrm{V}_{\mathrm{f}}\right)$ de un río, menor será la actividad neotectónica que represente; mientras que valores bajos indican mayor excavación del mismo y mayor actividad tectónica. Los valores bajos de encajonamiento corresponden a valles estrechos y profundos, mientras que los valores altos corresponden a valles anchos y someros.

En la cuenca Migriño, los valores del $V_{f}$ más bajos se localizan en el perfil A-A' ubicado en la parte alta de la cuenca, los otros perfiles B-B' y C-C' muestran valores ligeramente mayores a los del perfil A-A' (Figura 7a). Los valores más bajos de $\mathrm{V}_{\mathrm{f}}$ corresponden al cauce del arroyo Migriño, localizado al inicio de los tres perfiles topográficos de la figura 8 . Otros valores bajos como 0.16 y 0.13 , corresponden a la parte alta de los arroyos Las Truchas y Hondo (perfil A-A'), y de 0.15 próximo a la desembocadura del arroyo Las Truchas (perfil C-C').

En la cuenca de drenaje El Salto los valores de $\mathrm{V}_{\mathrm{f}}$ más bajos, 0.39 se localizan en la parte alta de los arroyos Salto Seco y El Salto (Figura 7b, perfiles A-A' y B-B'). Aguas abajo los valores de $\mathrm{V}_{\mathrm{f}}$ se incrementan, hasta alcanzar, en la parte baja, 2.37 en el arroyo Salto Seco y 3,81 en el arroyo El Salto (perfil C-C').

Los valores de encajonamiento en la cuenca de drenaje El Tule presentan una variabilidad similar a la encontrada para El Salto; valores bajos $(0.36$ y 0.23$)$ en la parte alta de la cuenca del arroyo El Tule (Figura 7c, perfiles A-A' y B-B') y valor se incrementa aguas abajo hasta alcanzar 2.1 cerca de la desembocadura (perfil D-D').

\section{Discusión}

\subsection{Tasas de erosión hídrica}

Como se muestra en la Figura 3 se encontraron diferencias en las tasas de erosión que dominan en cada una

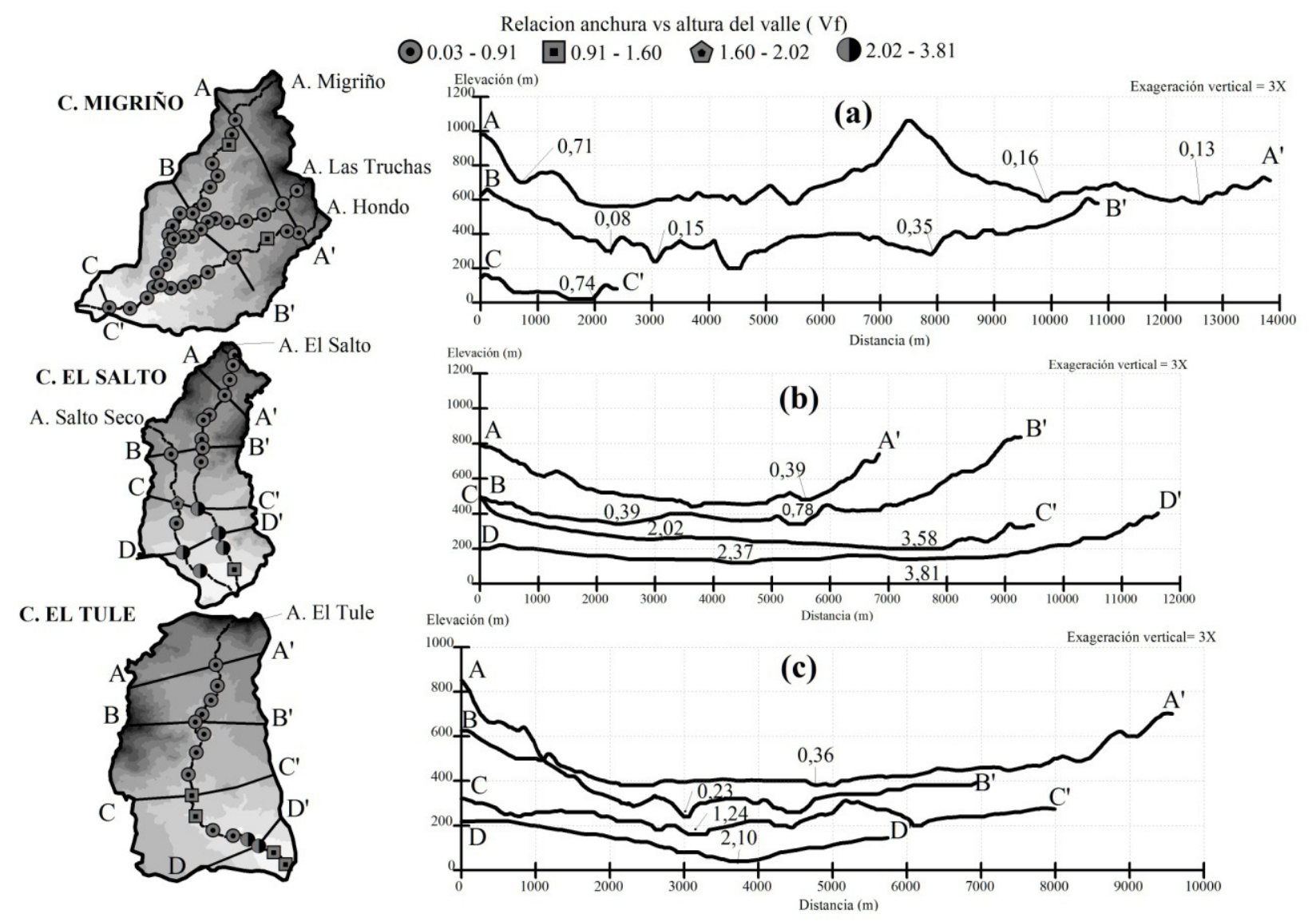

Figura 7. Índice geomorfológico que refleja la relación entre la anchura y la altura del valle $\left(\mathrm{V}_{\mathrm{f}}\right)$. Nótense los valores altos que se obtuvieron en la cuenca Migriño y los valores bajos obtenidos en El Salto y El Tule. La exageración vertical en los perfiles topográficos es de 3X. 
de las cuencas de drenaje estudiadas. En la cuenca Migriño la tasa de erosión que domina es moderada $\left(0.1 \mathrm{a} 0.5 \mathrm{Mg} \mathrm{ha}^{-1}\right.$ año ${ }^{-1}$ ), en El Salto domina sustancialmente la tasa de erosión baja $\left(0-0.1 \mathrm{Mg} \mathrm{ha}^{-1}\right.$ año $\left.^{-1}\right)$, mientras que en El Tule domina la tasa de erosión baja $\left(0-0.1 \mathrm{Mg} \mathrm{ha}^{-1}\right.$ año $\left.^{-1}\right)$ pero también es considerable la erosión moderada como se puede observar en la tabla 1. Existe una relación estrecha entre las unidades geomorfológicas, la pendiente del terreno y la distribución de las tasas de erosión. De tal manera que las tasas de erosión alta se encuentran asociadas a sierras, en donde la pendiente es igual o mayor a $35^{\circ}$. Cabe mencionar también que el patrón estructural favorece el efecto erosivo de las laderas; en zonas con mayor fracturamiento se intensifica la erosión, tal como se observa en la cuenca Migriño, en donde debido al fracturamiento intenso, los procesos erosivos dominan en la mayor parte de la cuenca. Lo contrario sucede en las cuencas El Salto y El Tule, dominadas por lomeríos y planicies con pendientes menores a los $5^{\circ}$, y las unidades de sierras están restringidas a la parte alta de las cuencas y en sus flancos. Por lo anterior en estas dos cuencas están presentes tanto los procesos erosivos como los de depósito, sin embargo dominan los segundos. Como evidencia de ello se tiene la presencia de las zonas de almacenamiento, que son mayores en El Salto y El Tule en comparación con la de la cuenca Migriño. Además, comparando los mapas de litología y edafología con el modelo de erosión se encuentra que la litología no es condicionante para la distribución de ciertas tasas de erosión, mientras que con los tipos de suelo sucede lo contrario, los Litosoles-Regosoles están asociados a tasas de erosión moderada a alta y los Regosoles a tasas de erosión baja.

La erosión en los cauces es también una fuente importante de sedimentos, por lo que se ha asociado la densidad de drenaje (Figura 4) con la producción de sedimento. Los valores de densidad de drenaje en las cuencas de estudio varían de 0.001 a $0.1 \mathrm{~km} \mathrm{~km}^{-2}$. Estos valores pueden ser convertidos a tasa de erosión del suelo considerando el volumen de suelo removido para formar un canal de drenaje y su edad promedio. Considerando lo que mencionan Hughes y Prosser (2003) quienes señalan que si se considera una sección transversal, con un área de $10 \mathrm{~m}^{2}$, en un cauce de $1 \mathrm{~km}$ de longitud, este debería de producir $10000 \mathrm{~m}^{3} \mathrm{~km}^{-2}$ es decir 15000 toneladas aproximadamente de sedimento. Y si este es erosionado de un cauce típico con una edad de 100 años la tasa media anual de erosión seria de $15 \mathrm{Mg} \mathrm{ha}^{-1}$ año $^{-1}$. Considerando lo anterior se estima que la tasa promedio de erosión asociada a la red de drenaje de primer pudiera varía entre 3.3 a $4.2 \mathrm{Mg} \mathrm{ha}^{-1} \mathrm{año}^{-1}$, sin embargo esto requiere de validación en campo.

\section{2. Índices geomorfológicos}

Los valores de forma de la cuenca $\left(\mathrm{B}_{\mathrm{s}}\right)$ para Migriño son de 1.8, para El Salto de 2.3 y de 1.8 para El Tule. Estos valores son mayores a la unidad, lo que indica que las tres cuencas son alargadas y jóvenes, asociadas a actividad neotectónica. La cuenca El Salto con el valor mayor de $\mathrm{B}_{\mathrm{s}}$, es más alargada que las otras dos, característica que se asocia al patrón estructural con rumbo NNW-SSE (NavarroLozano, 2006) y a la posición de la sierra baja en el área de la punta Cabo San Lucas, la cual brinda protección a la zona de descarga de la cuenca El Salto, permitiendo el desarrollo de un abanico aluvial más extenso que en las otras dos cuencas.

Con respecto al índice de sinuosidad del frente montañoso, $\mathrm{S}_{\mathrm{mf}}$, en la cuenca Migriño no se definieron frentes montañosos debido a que la mayor parte de su área presenta sierras con pendientes fuertes y no son claros los cambios de frentes motañosos (Figura 5). Las otras dos cuencas presentan frentes motañosos en sus partes alta y media con valores de 1.15 en la cuenca El Salto y de 0.7 a 1.13 en El Tule. En la parte media de ambas cuencas se definieron frentes montañosos en la Sierra La Chinche, que es el parteaguas entre estas dos cuencas, con valores mayores que los obtenidos en la parte alta, por lo que se deduce que el fallamiento normal con rumbo NW-SE de la parte alta de las cuencas es de mayor actividad, y por ello los frentes montañosos tienen una morfología casi rectilínea. Los mayores valores de $\mathrm{S}_{\mathrm{mf}}$ en la parte media de ambas cuencas reflejan menor actividad del fallamiento, evidenciado tanto por frentes montañosos más sinuosos, atacados por los procesos erosivos, así como por la presencia en estos frentes montañosos de depósitos de piedemonte observados directamente en campo. Así, los frentes montañosos de la parte media están asociados al fallamiento secundario (NE-SW), el cual podría ser de menor actividad que el fallamiento NW-SE que domina en el área. Rockwell et al. (1984), y Silva et al. (2003) señalan que para la Clase 1 el levantamiento tectónico esperado es superior a $0.5 \mathrm{~m} \mathrm{Ka}^{-1}$, mientras que para la Clase 2 está comprendido entre $0.5 \mathrm{y}$ $0.05 \mathrm{~m} \mathrm{Ka}^{-1}$, y para la Clase 3 el levantamiento tectónico es inferior a $0.05 \mathrm{~m} \mathrm{Ka}^{-1}$. Esta clasificación es semicuantitativa del grado relativo de la actividad tectónica de los frentes.

Los índices del gradiente del perfil longitudinal del cauce de los arroyos (SL) presentan una tendencia normal, con valores altos en la cabecera del arroyo, disminuyendo hacia la desembocadora. No obstante, en algunos puntos se encuentran valores altos del SL a lo largo del perfil, incluso cerca de la desembocadura (Figuras 6), los cuales coinciden con tres rasgos principales, que junto con el análisis de los perfiles topográficos se interpretan de la manera siguiente: (1) los cambios litológicos entre los depósitos de granodiorita-tonalita y los depósitos sedimentarios de conglomerados y arenisca-conglomerádicas, (2) el control estructural con rumbo predominantemente NW-SE, y (3) los valores altos de SL en la parte baja de las tres cuencas (15.1 en Migriño, 5.1 y 5.2 en la cuenca El Salto, y 11.7 y 12.3 en El Tule) están relacionados con antiguos niveles base de erosión.

Comparando los valores de sinuosidad del frente montañoso $\left(\mathrm{S}_{\mathrm{mf}}\right)$ y encajonamiento del cauce del arroyo $\left(\mathrm{V}_{\mathrm{f}}\right)$ se observa en la cuenca Migriño, que aunque no 
se definieron frentes montañosos, los valores de $\mathrm{V}_{\mathrm{f}}$ son menores o ligeramente mayores a 0.5 , con lo cual se infiere que esta cuenca está dentro de la Clase 1 propuesta por Bull y McFadden (1977) y en las cuencas El Salto y El Tule la comparación de los índices $\mathrm{S}_{\mathrm{mf}} \mathrm{y}_{\mathrm{f}}$ indica que éstas pueden ser clasificadas dentro de la Clase 2. Rockwell et al. (1984) y Silva et al. (2003) señalan que para la Clase 1 el levantamiento tectónico esperado es superior a $0.5 \mathrm{~m} / \mathrm{Ka}$, mientras que para la Clase 2 está comprendido entre $0.5 \mathrm{y}$ $0.05 \mathrm{~m} / \mathrm{Ka}$. Además, considerando lo reportado por Ortlieb (1987), que encuentró una relación de ascenso de 0.1 a 0.3 $\mathrm{m} / \mathrm{Ka}$ para la parte sur de la península de Baja California, Entonces de manera general se encuentra que las tres cuencas de drenaje están sujetas a una actividad tectónica de moderada a casi nula

\section{Conclusiones}

La aplicación de la formula RUSLE permitió encontrar que el control estructural, la pendiente del terreno y los diferentes tipos de suelo son los principales factores que determinan la erosión del suelo en las cuencas. Así, el intervalo promedio de erosión en la cuenca Migriño es de 0.1 a $0.5 \mathrm{Mg} \mathrm{ha}^{-1}$ año-1 mientras que en las cuencas El Salto y El Tule la tasa promedio de erosión es menor a 0.1 $\mathrm{Mg} \mathrm{ha}^{-1}$ año $^{-1}$. El análisis de los índices geomorfológicos indica que las tres cuencas son alargadas y jóvenes, asociadas a actividad neotectónica de moderada a casi nula, en donde el fallamiento normal con rumbo NW-SE presenta mayor actividad que el fallamiento secundario con rumbo NE-SW. Este nivel de actividad tectónica variado permite que en la parte media y baja de las cuencas El Salto y El Tule se presenten procesos de erosión-deposito, asociados a geoformas como planicies y abanicos aluviales, principalmente en la cuenca El Salto, mientras que en la cuenca Migriño dominan los procesos erosivos.

\section{Agradecimientos}

Damos las gracias al grupo de Geología Marina del CICIMAR por el apoyo otorgado para el desarrollo de este trabajo. A los proyectos CONACYT25274, y SIP20090845. A la Dra. Patricia Candelaria Montiel García por los comentarios que enriquecieron al trabajo.

\section{Referencias}

Best, T., Griggs, G.B., 1991, A sediment budget for the Santa Cruz littoral cell.: Society of Economic Paleontologists and Mineralogists Special, 46, 35-50.

Bird, E., 2001, Coastal Geomorphology an Introduction: John Wiley and Sons, LTD, $322 \mathrm{p}$.
Blair, T.C., McPherson, J.G., 1994, Alluvial fan processes and forms, en Abrahams and Anthony J. Parsons (eds), Goemorphology of Desert Environments, Athol D. Chapman \& Hall, London, 354-402.

Bull, W.B., 1978, Geomorphic tectonic activity classes of the south front of the San Gabriel Mountains, California: U.S. Geological Survey Contract Report 14- 08-001-G-394, Office of Earthquakes, Volcanoes, and Engineering, Menlo Park, California, 100 p.

Bull, W., McFadden, L., 1977, Tectonic geomorphology north and south of the Garlock Fault, California, en Doehring, D.O. (ed), Arid regions: Publications in Geomorphology, State University of New York at Bingamton, 115-139.

Canon, P.J.,1976, Generation of explicit parameters for a quantitative geomorphic study of the Mill Creek drainage basin: Oklahoma Geology Notes, 36, 1, 3-16.

Carvajal, R., Sanz de Galdeano, C., 2008, Aplicación de índices geomorfológicos al estudio de la cuenca del río Adra (Almería): Cuaternario y Geomorfología, 22 (1-2), 17-31.

Demek, J., (Ed.), 1972, Manual of detailed geomorphological mapping, International Geographical Union, Commission on Geomorphological Survey and Mapping, Prague, 344 p.

Faran Ali, K., De Boer, D.H., 2003, Construction of sediment budgets in large-scale drainage basins: the case of the upper Indus River: IAHS, 279, 206- 215.

Fletcher, J.M., Munguía-Orozco, L., 2000, Active continental rifting in southern Baja California, México: implications for plate motion partitioning and the transition to sea floor spreading in the Gulf of California: Tectonics, 19, 6, 1107-1123.

Frizzel, Jr V.A., Fox, L.K., Mooser, F.C., Ort, K.M., 1984, Late Cretaceous granitoids, Cabo San Lucas Block, Baja California Sur, México: EOS, Transactions - American Geophysical Union, 65, 1151.

García, E., 1981, Modificaciones al sistema de clasificación climática de Koppen, adaptado para las condiciones de la República Mexicana:

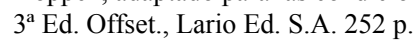

Hack, J.T., 1973, Stream-profile analysis and stream gradient index: U.S. Geological Survey Journal of Research, v. 1, 421-429.

Hughes, A., Prosser, I., 2003, Gully and riverbank erosion mapping for the Murray-Darling Basin, CSIRO Land and Water Technical Report No 3/03. Canberra: CSIRO Land and Water. (http://www.clw.csiro. au/publications/technical2003/tr3-03.pdf)

Instituto Nacional de Estadística, Geografía e Informática (INEGI), 1984, Carta Edafológica San José del Cabo F12-2-3-5-6, 1:250000: Secretaría de Programación y Presupuesto, Instituto Nacional de Estadística, Geografía e Informática, 1 mapa.

Instituto Nacional de Estadística, Geografía e Informática (INEGI), 1984; Carta Geológica San José del Cabo F12-2-3-5-6, 1:250,000: Secretaría de Programación y Presupuesto, Instituto Nacional de Estadística, Geografía e Informática, 1 mapa.

Inman, D.L., 2003, Litoral Cells, en Schwartz M. (ed) Enciclopedia of Coastal Science, The Earth Science Encyclopedia Online (www. eseo.com), with permission from Kluwer Academic Publisher, Dordrecht, The Netherlands.

Jenness, J., 2006, Topographic Position Index (tpi jen.avx) extension for ArcView 3.x, v. 1.3a (en línea), en Jenness Enterprises, Disponible en: <http://www.jennessent.com/arcview/tpi.htm>, consultado 12 de junio del 2010.

Komar, P.D., 1998, Beach Processes and Sedimentation: Prentice Hall (2da. Edision), $429 \mathrm{p}$.

McKergow, L. A., Prosser, I. P., Hughes, A. O., Brodie, J., 2005, Sources of sediment to the Great Barrier Reef World Heritage Area: Marine Pollution Bulletin., 51,1-4, 200-211.

Mitasova, H., Mitas, L., 1999, Modeling soil detachment with RUSLE 3d using GIS (en línea), Univeristy of Illinois at Urbana-Champaign, disponible en: <http://www2.gis.uiuc.edu:2280/modviz/erosion/ usle.html>, consultado 27 de Julio 2010.

Montes-León, M.A., Uribe-Alcántara, E.M., García-Celis, E., 2011, Mapa Nacional de Erosión Potencial: Tecnología y Ciencias del Agua, 2, 1, 5-17. 
Navarro-Lozano, J.O., 2006, Caracterización sedimentológica y geomofológica de los ambientes costeros en la Bahía San Lucas, Baja California Sur, México: La Paz, B.C.S., México, Centro Interdisciplinario de Ciencias Marinas del Instituto Politécnico Nacional, Tesis de Maestría, 144 p.

Onori, F., De Bonis, P., Grauso, S., 2006, Soil erosion prediction at the basin scale using the revised universal soil loss equation (RUSLE) in a catchment of Sicily (southern Italy): Environmental Geology, $50,1129-1140$.

Ortlieb, L., 1987, Neotectonics and Quaternary sea level variations in the Gulf of California Region, México, en Nava-Sánchez, E.H., 1992, Sedimentología de la cuenca San Juan de Los Planes, Baja California Sur, México: La Paz, B.C.S., México, Centro Interdisciplinario de Ciencias Marinas del Instituto Politécnico Nacional, Tesis de Maestría, $180 \mathrm{p}$.

Phillips, J.D., 1991, Fluvial sediment budgets in North Carolina Piedmont: Geomorphology 4, 231-242.

Ramírez-Herrera, M.T. ,1998, Geomorphic assessment of active tectonics in the Acambay Graben, Mexican volcanic belt.: Earth Surface Processes and Landforms, 23,317-332.

Renard, K.G., Laflen, J.M., Foster, G.R., McCool, D.K., 1994, The Revised Universal Soil Loss Equation, en Lal, R. (ed.), Soil Erosion Research Methods, 2nd edition, Soil and Water Conservation Society and St. Lucie press, USA, $105-124$.

Rockwell, T.K., Keller, E.A., Johnson, D.L., 1984, Tectonic geomorphology of alluvial fans and mountain fronts near Ventura, California, en Morisava, M. y Hack, T.J. (eds), Tectonic Geomorphology: Publ. in Geomorphology, State University of New York at Binghmanton, 183-204.

Saraf, A.K., 2001, Drainage/lineament/roads density analyst extension (version 1.0). ESRI, Redlands, CA.
Shaaf, P., Böhnel, H., Pérez-Venzor, J.A., 2000, Pre-Miocene palaeogeography of the Los Cabos Block, Baja California Sur: geochronological and palaeomagnetic constraints: Tectonophysics, $318,53-69$.

Silva, P.G., Goy, J.L, Zazo, C., Bardají, T., 2003, Fault-generated mountain fronts in southeast Spain: geomorphologic assessment of tectonic and seismic activity: Geomorphology, 50, 203-225.

Simms, A.D., Woodroffe, C.D., Jones, B.G., 2003, Application of RUSLE for erosion management in a coastal catchment, southern NSW. In Proceedings of MODSIM 2003: International Congress on Modelling and Simulation, volume 2, Integrative Modelling of Biophysical, Social and economic Systems for Resource Management Solutions, Townsville, Queensland, 678-683.

Walling, D.E., Collins, A.L.,2008, The catchment sediment budget as a management tool: Environmental Science and Policy, 11, 136-143.

Wasson, R.J., Olive, L.J., Rosewell, C.J., 1996, Rates of erosion and sediment transport in Australia: IAHS, 236, 139-148.

Weiss, A. 2001. Topographic Position and Landforms Analysis. Poster presentation, ESRI User Conference, San Diego, CA. In Jenness, J. 2006. Topographic Position Index (tpi jen.avx) extension for ArcView 3.x, v. 1.3a (en linea). Jenness Enterprises, disponible en $<$ :http://www.jennessent.com/arcview/tpi.htm>, consultado $12 \mathrm{de}$ junio del 2010.

Manuscrito recibido: Diciembre 8, 2010.

Manuscrito corregido recibido: Mayo 3, 2011.

Manuscrito aceptado: Mayo 14, 2011. 